\title{
Steady Flow Liquid Shielding Design for HYLIFE-II
}

\author{
P.A. House
}

February 7, 2000

U.S. Department of Energy

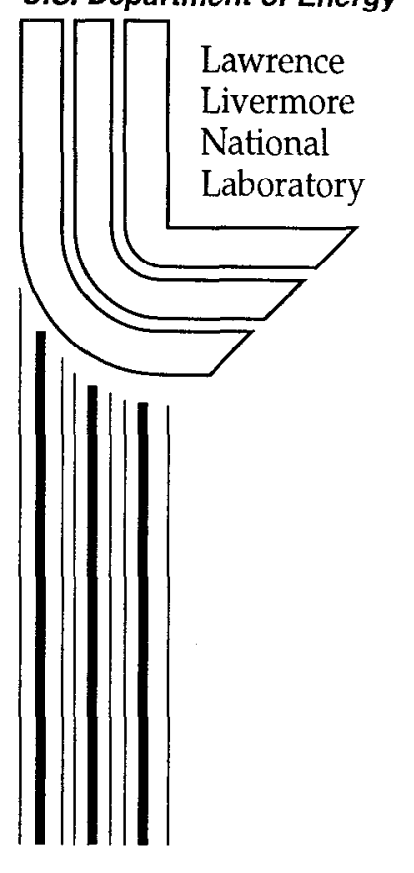




\section{DISCLAIMER}

This document was prepared as an account of work sponsored by an agency of the United States Government. Neither the United States Government nor the University of California nor any of their employees, makes any warranty, express or implied, or assumes any legal liability or responsibility for the accuracy, completeness, or usefulness of any information, apparatus, product, or process disclosed, or represents that its use would not infringe privately owned rights. Reference herein to any specific commercial product, process, or service by trade name, trademark, manufacturer, or otherwise, does not necessarily constitute or imply its endorsement, recommendation, or favoring by the United States Government or the University of California. The views and opinions of authors expressed herein do not necessarily state or reflect those of the United States Government or the University of California, and shall not be used for advertising or product endorsement purposes.

Work performed under the auspices of the U. S. Department of Energy by the University of California Lawrence Livermore National Laboratory under Contract W-7405-Eng-48.

This report has been reproduced directly from the best available copy.

Available to DOE and DOE contractors from the Office of Scientific and Technical Information

P.O. Box 62, Oak Ridge, TN 37831

Prices available from (423) 576-8401

http://apollo.osti.gov/bridge/

Available to the public from the National Technical Information Service

U.S. Department of Commerce 5285 Port Royal Rd., Springfield, VA 22161 http://www.ntis.gov/

OR

Lawrence Livermore National Laboratory

Technical Information Department's Digital Library

http://www.llnl.gov/tid/Library.html 


\title{
Steady Flow Liquid Shielding Design for HYLIFE-II*
}

\author{
Palmer A. House \\ University of California \\ Lawrence Livermore National Laboratory \\ P.O. Box 808 \\ Livermore, California 94550 \\ February 7, 2000
}

\begin{abstract}
A design concept is outlined in this report that utilizes only steady flow Flibe jets, with no moving parts inside the vessel. This design for liquid wall shielding is less complex than our present oscillating flow baseline design. The design avoids the wear and mechanical complexity of moving nozzles or deflectors inside the reactor vessel. Also the attaining of well defined liquid boundaries is less difficult than for the oscillating "slab" flow.
\end{abstract}

\section{Introduction}

The design is illustrated in Figure 1. The region surrounding the detonation point is bounded by a ceiling and four sides. Two of the sides are formed by the beam cross-flow shielding jets. The other two sides are formed by horizontal jets normal to the paper in Figure 1. The ceiling is made up from several horizontal slab jets. The bottom is open to allow unrestricted direct vapor venting (Peterson, 1998). The rapid venting will greatly reduce the pressure driven gross fluid velocity toward the vessel walls. Rapid venting will also reduce the vapor and "torn off" liquid debris entering the beam paths and tubes. In the oscillating flow HYLIFE design (Moir et al, 1994) the detonation point is located inside a pocket, created by the oscillating flow. As a result, less area for venting is available and venting time will be extended.

\section{Shielding and beam access}

While the open bottom is very desirable from the standpoint of venting, it does expose a large portion of the vessel wall below the shot point to a direct view of the detonation. Thus a $0.5 \mathrm{~m}$ thickness of Flibe must be provided to shield the metal walls. The method of providing this shielding is shown in Figure 2 (90 Degrees from the view in Fig. 1). The lower part of the vessel has a funnel shape. Flibe enters an annular flow area near the bottom and flows upward to an annular nozzle at the top. From this nozzle Flibe leaves at about $2 \mathrm{~m} / \mathrm{s}$, with a thickness of $0.5 \mathrm{~m}$, and flows downward over the inner wall of the 
vessel. Velocity of the Flibe increases due to the acceleration of gravity. Thinning of the Flibe thickness is negated by the funnel shape of the inner wall, where the reduction of flow area compensates for the increased velocity and allows a nearly constant thickness to be maintained.

In Fig. 1 notches in the annular nozzle are shown that allow space for the horizontal ceiling nozzles and flow receiver. At the exit of the exposed ceiling flow, Flibe enters a receiver where the fluid can be connected to a diffuser for head recovery. In Fig. 2 a turning vane is shown that directs the horizontal shielding jet downward. Figure 2 also illustrates how the heavy ion beams enter the chamber. The vessel wall is penetrated by a beam tube for each beam. A vortex shielding device (House, Moir, 1999) is attached to. the end of the beam tube to provide shielding for the tube end and inside surface. Fig. 3 is a top view that shows locations of all of the jets and turning vanes. The dashed lines in Figures 2 and 3 illustrate the space where 96 neutral beams per side, enter the vessel. For a portion of beams, annular flow will flow around the beam tubes.

The shot point (Figures $1 \& 2$ ) is located $0.5 \mathrm{~m}$ below the ceiling flow. This location will not allow for gravity clearing of debris between the shot point and the ceiling flow, at 4 and $6 \mathrm{~Hz}$. Vapor blow-off is in the downward direction, this will induce downward velocity to the debris. Isochoric heating spall from the ceiling jet will have both downward and horizontal velocity components and will likely clear beam paths before the next shot. Isochoric heating spall from the beam cross flow shielding jets will have both 45 degree downward velocity and shot induced horizontal (toward the center) velocity. One problem to try to avoid, is having spall from the beam shiclding streams meet in the center and jet in all directions in a vertical plane. Perhaps the beam shielding jets can be shaped or slanted to prevent a collision with spall from the opposing jets. The whole question of beam path clearing needs more analysis and design work in the future.

\section{Design considerations}

Loads on the first wall and circumferential distribution will need to be determined for this first wall design. The loads will be produced by the neutron isochoric heating and subsequent expansion of the $0.5 \mathrm{~m}$ liquid flowing against the wall. If the first wall were made flexible then the loads would be transferred to the outer wall. The outer wall can then be reinforced, as required, to take the loads imposed. The $0.5 \mathrm{~m}$ liquid thickness will protect the first wall from low mass, high speed debris.

Another area that will need more thought and some experimental work is the interaction between the wall flow and the various shielding jets that will mesh and combine with it. The main concern is any thin zones in the wall shielding that might develop, caused by turbulence or eddics. "Splash back" toward the beam paths is to be avoided at all costs.

Figure 1 illustrates the design of the bottom of the reactor vessel. Features include a shielding pool and a diffuser for partial Flibe head recovery. This recovery in pressure 
will greatly reduce the electrical power needed to drive the Flibe pumps. In the HYLIFE-II oscillating flow mechanical design (House, 1992) head recovery efficiency was estimated to be $50 \%$.

Tables 1 and 2 list the Flibe flow rates estimated for operation at 4 and $6 \mathrm{~Hz}$ respectively. The $76.5 \mathrm{~m}^{3}$ total for $6 \mathrm{~Hz}$ is nearly the same as the $73.9 \mathrm{~m}^{3}$ calculated for HYLIFE-II, with beams from only one side (House, 1992).

This report describes a design concept to avoid moving parts inside the vessel and allow for more rapid venting. Much more design, analysis, and experimental work will be needed to arrive at a practical design which addresses and solves the problems brought up. The principal goals are adequate shielding for all metal parts, beam path clearing between shots and increased reliability inherent in elimination of moving parts inside the vessel.

This work was performed under the auspices of the U. S. Department of Energy by the University of California, Lawrence Livermore National Laboratory under Contract No. W-7405-Eng-48.

\section{References}

1 P. F. Peterson, UC Berkeley, private communications, 1998

2 R. W. Moir, et al (1994), "HYLIFE-II: A Molten Salt Inertial Fusion Energy Power Plant Design-Final Report", Fusion Technology 25, 5-25 (1994)

3 P. A. House, R. W. Moir (1999), "Beam Line Protection Vortex", Patent Disclosure, IL-10506

4 P. A. House (1992), "HYLIFE-II Reactor Chamber Mechanical Design: Update", UCRL-ID- 109429 
Table 1. Flibe flow rates at $4 \mathrm{~Hz}$

\begin{tabular}{|c|c|c|c|c|}
\hline$\frac{\text { Flow type }}{-}$ & $\frac{\text { Area (total) }}{\left(\mathrm{m}^{2}\right)}$ & $\frac{\text { Velocity }}{(\mathrm{m} / \mathrm{s})}$ & $\frac{\mathrm{Q}}{\left(\mathrm{m}^{3} / \mathrm{s}\right)}$ & $\frac{\text { Power }}{(\mathrm{MW})}$ \\
\hline Funnel & 10.21 & 2 & 20.4 & 0.08 \\
\hline Ceiling & 0.5 & 16 & 8 & 2.05 \\
\hline Side blocking & 0.58 & 14 & 8.1 & 1.59 \\
\hline Beam shielding & 2.56 & 8 & 20.5 & 1.31 \\
\hline Spray nozzles & 0.1 & 12 & 1.2 & $\underline{0.17}$ \\
\hline & & To & $=58.2$ & 5.20 \\
\hline
\end{tabular}

Table 2. Flibe flow rates at $6 \mathrm{~Hz}$

Flow type

Funnel

Ceiling

Side blocking

Beam shielding

Spray nozzles

\begin{tabular}{|c|c|c|c|}
\hline$\frac{\text { Area (total) }}{\left(\mathrm{m}^{2}\right)}$ & $\frac{\text { Velocity }}{(\mathrm{m} / \mathrm{s})}$ & $\frac{\mathrm{Q}}{\left(\mathrm{m}^{3} / \mathrm{s}\right)}$ & $\frac{\text { Power }}{(\mathrm{MW})}$ \\
\hline 10.21 & 2 & 20.4 & 0.08 \\
\hline 0.5 & 24 & 12 & 6.91 \\
\hline 0.58 & 21 & 12.2 & 5.37 \\
\hline 2.56 & 12 & 30.7 & 4.42 \\
\hline 0.1 & 12 & 1.2 & $\underline{0.17}$ \\
\hline \multicolumn{3}{|c|}{ Total $=76.5$} & 16.95 \\
\hline
\end{tabular}




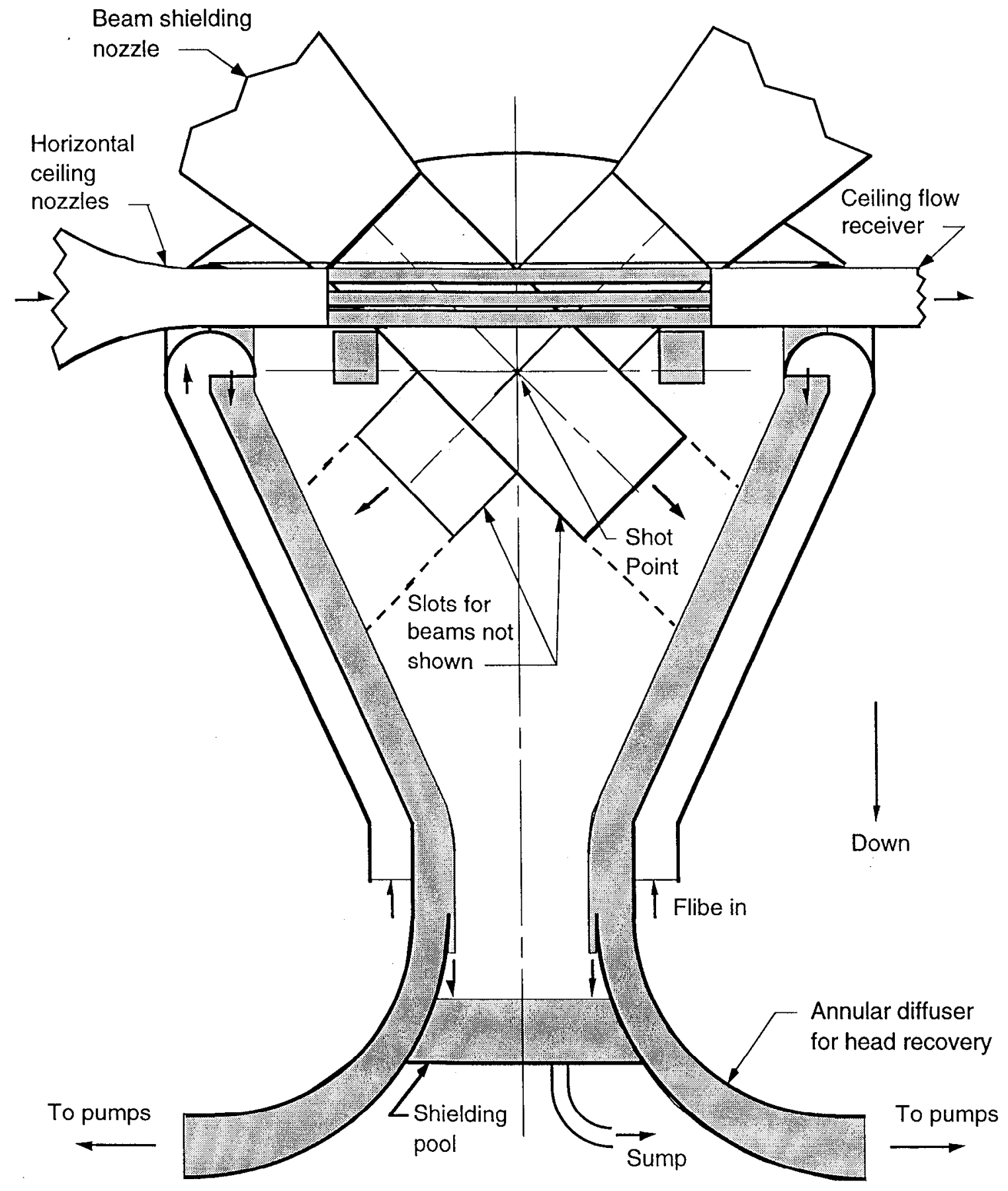

Fig. 1. Front section view and head recovery section

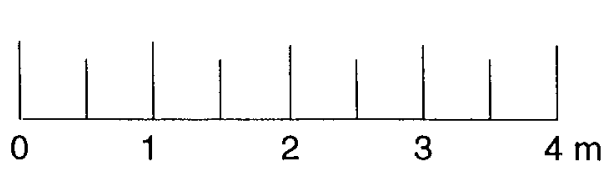

PAH

$1 / 26 / 00$ 
